\title{
The Place of Practice in Tertiary Popular Music Studies: An Epistemology
}

\section{Introduction}

The formation of the Association for Popular Music Education in 2011, the inclusion of a Popular Music Education grouping at the 2016 conference of the International Society of Music Education, and the 2017 first edition of the Journal of Popular Music Education, demonstrate clearly that the study of popular music pedagogies is gaining momentum as a discipline in its own right. And yet, there is to date little importance placed on the role of Popular Music Studies in this emerging field. What might be the role of Popular Music Studies in tertiary institutions offering degrees focusing on popular music practice? Could purely theoretical Popular Music Studies also inform creative practice in the education of the popular music practitioner? Richard Middleton (1993) described a dialogue between Popular Music Studies and musicology, and a desire to 'bridge the gap' between the two. In this article, it is argued that as Popular Music Education has emerged as a discipline, a similar tension has emerged, but between Popular Music Studies and Popular Music Practice. Echoing Middleton's thoughts: "I believe each needs the other" (1993: 177).

In the same way that musicology and sociology eventually found common ground in the so-called new musicology, it is proposed in this article that the time is right to bring Popular Music Studies and Popular Music Practice together under the banner of Popular Music Education. Just as Phillip Tagg (2012) asks cultural theorists to incorporate the sounds of the music into their research, and the cultural theorists asked the musicologists to consider music's cultural 
context, I ask that popular music practice educators consider the study of popular music from a sociological perspective as well as a practical one, and to consider the relevance of cultural theory and sociology to the practice of music making - its creation not just its performance - to their field. Contextualised primarily within the findings of Cloonan and Hulstedt's 2012 report which mapped higher education in popular music in the UK, this is approached firstly through a discussion of the evolution of Popular Music Studies and its relationship to Popular Music Education, and secondly through the presentation of case studies of how Popular Music Studies has been integrated into an Australian Popular Music Practice degree, how this was perceived by its students, and finishes with some suggestions as to how it might be best integrated.

\section{Terminology}

While recognizing regional variations, for the purposes of this article, Popular Music Studies is not presented as an overarching term for the study of popular music in all its forms, but rather is taken to define the study of popular music within its socio-cultural context, which is interdisciplinary in its approach encompassing, but not restricted to, cultural studies, sociology, musicology, and ethnomusicology. The term in its currency is generally not included in Popular Music Education literature, although this landscape is slowly changing. A Popular Music Practice program is defined as one in which the creation of music is the primary focus and major study and, for the purposes of this article, Popular Music Practice defines the acquisition of skills in music-making. The latter is not to be confused with Popular Music Pedagogy, which refers to the design, 
practices, methods, and approaches to the learning of the practice of popular music. It too can it be a problematic term. For example, in his study of discourses of Popular Music Pedagogy in a content analysis of journals related to popular music education, Roger Mantie identifies an obfuscation of PMS and Popular Music Pedagogy, describing how:

those who cite the work of Lucy Green as evidence of support for the study of popular music ... entextualise (sic) her work as advocating for the inclusion of popular music in the curriculum, even though a close reading of Green's work shows that she primarily is interested in the learning processes that occur in the course of engaging, especially informally, in popular music-making activities (2013: 347).

It is important therefore to note that while this article may be of interest to scholars of Popular Music Pedagogy, it is not of specific relevance to the topic of this article. The focus here is on Popular Music Studies (PMS) and Popular Music Practice, as defined above, considered as two separate (but related) branches of Popular Music Education (PME): it is the relationship between the two that informs the argument presented in this article.

Phillip Tagg points to a 'bizarre institutional and epistemic gap between the Nothing-But-The-Music and Everything-Except-The-Music poles of music studies (NIMiMS). This is an issue which the recently (2015) formed Network for the Inclusion of Music in Music Studies (NIMiMS), aims to address. While there is arguably a long way to go before NIMiMS finds its momentum, I would like to 
extend the discussion taking place in NIMiMS to one that addresses another institutional gap, one that, paraphrasing Tagg's words, points to a bizarre institutional gap between Nothing-But-Music-Studies, and Nothing-But-Music Practice. NIMiMS is a relevant starting point for discussion of the relevance of PMS to Popular Music Practice. On the website for NIMiMS, Tagg states 'We ... have often been frustrated in our efforts to relate part to its meanings and uses, and to relate those meanings and uses back to the musical sounds with which they are demonstrably linked' (NIMiMS). He describes the aim of NIMiMS as 'to break our isolation and to give us a concerted voice with a view to integrating the sounds of music into the study of culture and society' (NIMiMS).

The network describes its aims broadly as to bridge gaps between the practical and theoretical aspects of the study of music as well as between music as sound and culture, and to develop ways that non-musicians can engage with the study of music as sound. For example Tim Wise (Salford) supports 'developing new approaches to the teaching of music to young people that will encourage both their participation in music making and their understanding of music's structures' (NIMiMS. Italics added). This article expands on the ideas put forward through NIMiMS by discussion of the potential interplay between the study of popular music as text, in context, and as practice. With the aim of identifying the intersections which would enrich and unite all three in a more holistic trans-disciplinarity, the student of music practice is placed at the center of this model rather than the student of musicology.

\section{Background}


The International Association for the Study of Popular Music - IASPM - was established in 1981, the result of the emergence of popular music as a serious field of academic study, with a primary aim of reconciling a perceived divide between musicology and sociology. Lacasse describes how 'this divide was actually to remain a challenge for many years' and that at the time, 'the study of popular music was, at best, multidisciplinary but not (yet) interdisciplinary' (2015: p.68). He notes how the formation of IASPM created a challenge in the form of a 'disciplinary Babel Tower that had to be circumvented, especially with regards to methods of analysis and the "sociological/musicological" epistemological divide' (Lacasse 2015: 67). The birth of IASPM led, directly and indirectly, to the emergence of many popular music journals, academic publications and related associations yet Martin Cloonan argues that 'over thirty years after the founding of IASPM our research shows that fundamental questions remain about what the study of Popular Music could and should be' (2013: 76): it is argued here that the role of PMS in Popular Music Practice should be one of those fundamental questions.

PMS as a discipline is the extension and maturation of new musicology, which itself emerged in the 1970s and became a blanket term which encompassed a range of new approaches to musicology and which could be said to have come to maturity in the 1990s, the formation of IASPM being a key point on this journey. As a reaction to the inability of formal (Classical) analytical methods to effectively deconstruct popular music, new musicology incorporated new approaches which allowed not only for the incorporation of sociological and cultural context, but also focused more on, for example, the connotations of 
musical gestures and the impact of technologies (amplification, sound manipulation, audio production etc.).

Cloonan notes that the new musicology was a 'key factor which shaped the development of PMS' and 'put the serious study of popular music on the academic agenda' (2005: 79). Spearheaded by Richard Middleton, John Covach, Robert Fink, Stan Hawkins, Allan Moore and others, these scholars and others essentially all propose similar solutions to bridge the divide between cultural studies and musicology: that musicology had to fundamentally change itself to become more concerned with the social aspects of popular music and how that music is received. Cloonan explains how:

These two approaches - the textual and the extra-textual - can be seen as forming the two paths down which Popular Music Studies has subsequently walked. The limitations of purely textual approaches left the field of Popular Music Studies open to the sociologists and others from the social sciences who sought to locate popular music within broader sociopolitical and cultural trends (2005: 80).

Sociologists like Andy Bennett encouraged PMS to also include study of the audiences who consume the music and so 'begin to appreciate how musical taste, rather than simply being a product, is ...one of the available means through which individuals are able to actively construct their identity, lifestyle and even sense of place' (2008: 14). Identity, place, function, lifestyle, gender, audiences, 
amongst others have now become standard approaches to the study of popular music.

The history of the development of PMS has been well documented and discussed at length (see for example Richard Middleton, Robert Fink, Andy Bennett, Martin Cloonan, Simon Frith) and the role of 'the music itself' has been amply covered through the discourse of new musicology. Hesmondhalgh and Negus propose that:

the study of popular music is, at its best, a uniquely interdisciplinary area of research, drawing significant contributions from writers within a number of academic fields including musicology, media and cultural studies, sociology, anthropology, ethnomusicology, folkloristics, psychology, social history and cultural geography (2002: 2).

Cloonan suggests that 'there is some consensus amongst Popular Music Studies scholars that it is not a discipline in its own right, rather it is a field of study which appears to have only one unifying factor - its study of popular music' (2005: 83). While Cloonan did not intend Popular Music Practice to be included in this statement, it nonetheless rings true and if the study of popular music is at its basis, then it should be inclusive of its practice, yet the role of PMS in PME has received little attention.

John Covach claims that 'the problem lies in the assertion that there is a single way to view popular music, as inherently and primarily social [however] popular 
music can also be considered as inherently musical and only secondarily social' (2001: 464). I would argue that from the practitioner's point of view, popular music is always inherently musical, and herein lies part of the challenge of integrating PMS into a program focussed on popular music practice. Covach supports this in saying that 'the study of popular music opens up new repertoires and introduces fresh perspectives on current issues in musicology; thus, it expands our understanding of the history of music and enriches our relationship to music itself' (2001: 470). While Covach may not have been referring directly to practitioners of popular music when he wrote this, the relevance is clear in that it puts the 'music itself' at centre stage. Likewise, Lee Marshall describes how music 'has a materiality to it, a materiality with both spatial and temporal dimensions. If we are to understand musical experience and musical meaning, we need to address these material aspects, to consider musical content as well as musical context' (Marshall 2011: 165). Marshall argues that 'if we are to develop better sociological understandings of musical experience, then it is necessary to consider the sounds that people hear as well as the ways in which they hear them' (2011: 172): yet even here the creator and the creation of the music is absent from the discussion.

\section{The Australian PMS landscape}

There are at least three areas to be considered when discussing the role of PMS in PME: the study of the music itself (musicology); the study of its context (PMS); and the relevance of both to those engaged in the study of the practice of popular music. In Cloonan and Hulstedt's report (2012), they group courses into practical (performance, songwriting), vocational (business, industry) and critical 
(musicology, PMS) ${ }^{1}$. Importantly, Cloonan and Hulstedt recognise the equal importance of critical theory to practice, and its relationship to vocation: this relationship will be discussed in further detail in the concluding section of this article. It is this interaction between the practical and the critical, noting inevitable overlap, and the ways they both inform practice and vocation that is under consideration. The following section outlines the results of a web survey of Australian institutions offering PMS, which portray the curricular landscape upon which this discussion is based.

In Australia, popular music practice degrees are growing, and yet Popular Music Practice is entirely absent from PMS, and PMS is underrepresented in Popular Music Practice programs. In 2015 I conducted a comprehensive survey of Australian tertiary institutions offering popular music practice degrees, and found no evidence of integration of PMS with PMP. Based on official web page descriptions and content, I analysed the structure of popular music programs (degrees) and courses (modules) in Australia, for comparison with those in the UK. I identified 415 degrees or programs that offered some form of study of popular music, 308 in the UK and 107 in Australia. Music Business and Music Technology were included in the count, however the field is dominated by popular music performance, or creative practice degrees. This also aligns with Cloonan and Hulstedt's 2012 report.

\footnotetext{
${ }^{1}$ In the report, the authors describe Popular Music Studies as the intersection of the three, however it is important to note here that what these authors refer to as popular music studies is not PMS as defined in this article, but rather the overarching study of popular music in its entirety (here defined as Popular Music Education).
} 
My survey identified the inclusion of courses which were categorized as PMS (popular music as a part of a greater social, cultural, and historical context); Popular Musicology (analytical tools for the analysis of popular music); Music Business (structural, marketing, promotional, and legal aspects of the music industry); Event Management (logistical aspects of musical events e.g. gigs, festivals, tours; artist management); and Education (pedagogy and teaching of popular music in community, school, and university environments). For the purpose of analysis, this survey distinguished between programs centered on music as a creative practice (e.g. songwriting, performance); technical audio or production degrees; and music business, but recognizes that there may be considerable overlap between these areas in specific programs.

In Australia $82 \%$ of universities offer popular music courses, compared to the UK where $47 \%$ of universities offer popular music courses. The survey identified 107 individual programs that offered popular music courses in Australia. Looking at programs dedicated to popular music practice, 33 were identified in Australia, of which only $30 \%$ offered courses in PMS. The report also looked at non-music programs offering courses in PMS. Compared to the data for music programs, the contrast is interesting, with more than double the proportion of PMS courses in non-music degrees. In most cases, these PMS courses were found in Humanities, Communication, and Media programs In other words, PMS dominates the study of music in non-music programs, but accounts for less than a third of courses in practical based music programs. This supports Tagg's proposal of a nothing-but-the-text and nothing-but-the-music divide, with that divide being institutionalised through course offerings. 
Two other popular music scholars who have investigated popular music education at tertiary level came to similar conclusions. Jon Fitzgerald conducted a study of 20 tertiary institutions offering PMS courses, 10 in Canada and 10 in Eastern Australia. Highlighting the challenges of clear definitions of the terminology presented in this article, Fitzgerald classifies PMS as inclusive of both theoretical and practical applications. Nonetheless, supporting the findings of this article, he found 'a clear tendency for non-music departments to focus on reception and context at the expense of production and text - while music departments mostly do the reverse' (2007: 3). Phil Hayward proposes that 'critical-historical and cultural-economic analysis should be a central concern for all music students, and not just treated as an extra and/or elective element added to production and performance...music is not a sphere of activity that exists outside of ideology, culture and economics, but rather is one fundamentally determined by and reflective of these aspects' (Fitzgerald \& Hayward 2004: 155).

\section{PMS in the practical curriculum}

Analysis of the data discussed above raises the same questions proposed by Cloonan: 'What is studied in such [popular music studies] courses, and how? What should be studied and how? In whose interest are current studies taking place? (2005: 78). Even Cloonan's observation that PMS has 'only one unifying factor - its study of popular music' (2005: 83) neglects the learning of popular music practice as a contributing factor. He does draw attention however to 'how many non-musicians are active within it' (2005: 84. Italics in original). This is 
not surprising given the data above, as it appears that in Australia at least, these courses are available to students studying music practice only where their programs allow enrolment into non-music program electives. He notes that 'it may be the case that the higher up one wants to study PMS, the less one needs to be a practicing musician' (2005: 84). This however is also a question of not only relevance, but of priorities. The opposite could also be proposed: the higher up a practicing musician aspires, the less they might need to engage in PMS. This is a question that is addressed further on.

Joe Bennett's chapter on popular music curricula is one of the few texts to directly address the relevance of PMS in Popular Music Practice - that is, in a creative practice educational context. He argues that 'a popular music education curriculum that focuses exclusively on the instrumentalist is unlikely to beget meaningful creative outcomes in terms of popular music's product. At best it will generate session musicians who can succeed in certain niche roles in the music industry' (Bennett, 2017: forthcoming). Bennett notes that 'PMS holds that popular music can be studied as a social, cultural or economic phenomenon rather than an aural, creative or musicological one' (2017: forthcoming. Emphasis added), which supports Tagg's description of the tension between musical text and context (2004). It is proposed here that PMS can be studied as well as popular music practice, and that it can, and should, form an essential part of the curriculum. Bennett argues, as I do here, for a more holistic approach to Popular Music Practice, of which PMS should be an important component, and which would inform and benefit creative practice. In Cloonan and Hulstedt's report, regarding the intersection of practical, theoretical and vocational one 
interviewee (DW - anonymous in report) supports this, noting that 'the balance definitely errs on the practical and the vocational, but that has to be couched in the degrees of consideration, critical thought' (2012: 27). How then should the critical be balanced with the practical, and how might that relate to the vocational? Two approaches are proposed below - the textual, and the contextual, both informing practice.

\section{Scenario 1: Popular musicology (the text) and practice}

The integration of new musicology into a popular music practice program was the topic of a recent survey of student impressions of the history and analysis courses in the Bachelor of Popular Music (BPM) program at Griffith University's (Australia) Queensland Conservatorium of Music (see Byron and Weston 2015). The BPM is a popular music practice focused program, and its pedagogical design is intended to replicate the informal learning practices of popular musicians in the broader community, within a formal educational context (Lebler 2007) as well as the structure and dynamics of the popular music industry (Lebler and Weston 2015), both informed by the concept of authentic learning experiences ${ }^{2}$. Graduate outcomes are dominated by alumni working within the music industry across a range of music-related vocations, but primarily as performers, songwriters and teachers. Each semester, students enrol into four courses, each from a designated stream. The Major Study stream is the core of the program assessment for this consists of the submission of a folio of original work at the end of each semester, written, performed, recorded and produced in

\footnotetext{
${ }^{2}$ Authentic learning encompasses learning practices that mirror real-world practices, assessment tasks that emulate real-world outcomes, and in which students enact the modes of practice of their discipline in their learning.
} 
collaboration with other BPM students or external musicians. Each semester, there is also an audio engineering/production course, a songwriting and music technologies directed course and a popular music history and analysis course, which is grounded in various aspects of new musicology.

While the traditional analysis of music has been a component of most classical and jazz programs, its role in popular music has been the subject of debate, sparking the evolution of new musicology and eventually PMS. Hawkins (2001) set out a case for popular musicologists which proposed not only a justification for the integration of musicology, sociology and cultural theory, but a focus on the equal importance of the musical and the paramusical in communicating meaning within a musical text. Instead of extracting theoretical meaning from the melody, rhythm, and harmony alone, the new musicology expounded here values analytical approaches such as musical semiotics that emphasize the meaning connoted behind musical gestures rather than their theoretical ramifications. This is in accord with the general rule of new musicology that the tools for analysis should be defined by the song itself, rather than by a uniform analytical paradigm.

In the BPM history and analysis courses, students are required to analyse music as a communicative medium within the semiotic analysis framework developed by Phillip Tagg, which takes into consideration traditional musical elements as well as more nuanced musical and paramusical aspects such as timbre, groove, production, and gesture (Tagg 2012). Specifically, over three years, students learn about the history of popular music in a chronological fashion, but do so 
through contextualization of the sounds of the music in their socio-cultural setting. In these courses music is studied not so much for its sound, but for the insights that it offers about culture and society. Meaning, significance and communication and how these are communicated through sounds, as music, are key components. The focus is on music not only as a form of artistic expression and as entertainment, but as a key cultural factor in people's lives, which may be expressed on a personal level, or on a societal level, such as a symbol of historical or cultural identity. In designing these courses, the key question was what kind of theoretical approaches to the study of popular music would benefit music practitioners? While the sounds are the primary focus of such analysis, in assessment tasks students are asked to interpret the music within its historical and social-cultural context, and to refer to relevant cultural and sociological theory such as gender, ethnicity, and historico-political context in the analytical process.

The rationale for these courses is that they would not only enhance critical listening skills, but also provide an understanding of the communicative qualities of music as well as the impact of context, which would eventually inform the students' own creative choices and practices. In our research, (Weston and Byron: 2015) we found that students expressed an initial resistance to the objective deconstruction of a perceived subjective art form, but in general, in their $3^{\text {rd }}$ year and post-graduation, students were able to articulate the benefits to their practice, as exemplified in comments such as one student who said 'I have noticed a massive improvement in my songwriting skills, which I believe has come from listening to different styles of music and really concentrating on 
the elements that make the song enjoyable'. Referring to performance, another student noted that 'semiotic analysis has basically, nice and neatly labeled and filed all the things I thought I was hearing in music before and now I am able to recreate it with new-found understanding'. And referring to both composition and practice, another student described how 'I now have the musicological tools and frameworks to understand formulas and patterns in the art of songwriting and musicianship' (Byron and Weston 2015: 67). Students were also able to articulate the intrinsic two way communicative process embodied in music, and which forms the basis of semiotic analysis, such as in this statement: 'I have a deeper idea of how to convey my ideas in my music, and properly interpret a song' (Byron and Weston 2015: 70). Clearly, studying the 'text in context' (semiotics) has benefitted these students in several aspects of their practice.

The first step therefore in integrating PMS into Popular Music Practice is to make the theory relevant to the creation of the music. With regard to popular musicology, this is less challenging, even when social context is included. For example, the critical listening skills acquired through the semiotic analysis of popular music aid the practitioner in considering on a deeper level the musical choices they make in their creative practice. Semiotic analysis also extends musical vocabulary, and in doing so opens up new modes of musical expression. This would be, for example, of particular value to the producer and/or session musician in developing their communication skills in the studio. It provides an understanding of how context and subjectivity influence not only the creation of music but also its interpretation, which is also of value to the music creator and practitioner. Through framing these courses in theory drawn from the new 
musicology components of PMS - in other words of bridging the divide between text and context - students expressed that understanding the relationship between musical sounds and cultural context informed their practice through developing critical listening skills and promoting the flow of new ideas.

\section{Scenario 2: PMS (the context) and practice}

While the students could see the benefit of the study of 'music as sounds' to their practice, and while indeed the study of sounds increasingly falls under the umbrella of PMS, engagement of Popular Music Practice students with purely theoretical PMS is more problematic. As part of an anonymous 2016 survey of 25 BPM graduates from the years 2005 - 2015, which was instigated with the aim of informing potential program changes, participants were asked a series of questions regarding the impact on their current employment of courses they had studied during their enrolment in the program. In part, these questions sought to answer a similar question to that posed by Cloonan, when he asked "what is the relationship between such courses, the music industries and broader academic trends?' (2005: 78). With the option to tick multiple boxes, the employment breakdown of the sample was $68 \%$ performing artist; $60 \%$ education (primary, secondary and tertiary); 48\% music business (events/marketing/management); 40\% audio engineer/producer; $28 \% 3^{\text {rd }}$ party songwriter; $20 \%$ private teaching practice; $20 \%$ session musician; $4 \%$ not music related. Breaking down the data further, primary income was derived from $48 \%$ teaching; 32\% performance; $12 \%$ recording studio; $8 \%$ non-music related.

These figures are consistent with the working profile of the contemporary music graduate, as will be discussed further on. 
One of the questions asked was in relation to the 'non-musical' aspects of their studies such as the research components of the history and analysis courses. For example, students may be asked to discuss in an essay a piece of music in the context of a given theory such as gender theory or identity, or as a subculture; they might be asked to consider audience theory and reception, performative aspects such as gesture, and/or more general theories of function and consumption. Students would also be expected to relate the music itself to these theoretical contexts, and there are set minimum numbers of cultural theory texts that must be referenced. In other words, these essays (and the lecture content they relate to) are clearly embedded in PMS.

Not surprisingly, given the employment breakdown, 33\% of respondents found these courses invaluable to their teaching, exemplified in comments such as 'Having a general, broad and interesting knowledge is valuable in the classroom'; 'Teaching music means that this is a very important area used when planning lessons'; 'They helped me shape my teaching habits and the grammatical knowledge and research methods involved help me to be a much more productive teacher.' This is an important point to consider given the growth in popular music programs in universities and also the integration of popular music into secondary classroom teaching especially in Australia where this has not previously been the case.

Interestingly, $25 \%$ of respondents claimed these courses had benefitted their non music-specific professional practice: 'they are useful for cognitive thinking 
which helps anyone in most employment situations'; 'these courses taught me to write and express my thoughts and requirements in an educated and professional manner. I am now able to better fulfil write ups and media requests'; 'The ability to put into words my opinions and observations is an invaluable resource when it comes to conducting interviews, running promo campaigns etc.'; 'I like the socio-cultural facets of music and history. I became more informed about the world and it helped to develop an interest in teaching.' These kinds of responses are supported by one of the interviewees (who wished to remain anonymous) in Cloonan and Hulstedt's report who said: 'it's right that they are encouraged to be critical and reflective and intellectual in their approach to it. I'm not necessarily sure that I would draw a hard distinction between practical provision and academic provision, because I would hope that within a university environment to be looking at module where... they were coming out with practical skills' (2012: 25).

\section{Synthesis}

The common factor with these responses is that each graduate related their learning to a vocational outcome that was not necessarily music performance specific, whereas in their responses to textual analysis, they clearly articulated benefits to their practice. Cloonan describes how 'when the vocational aspects ... are added into the mix, the result is that the theoretical parts of PMS courses often have a tokenistic feel to them' (2005: 87). However, the responses to the surveys above would appear to contradict this statement, even when the relevance was not direct, such as in the contextual aspects of the courses. Alf 
Bjornberg also supports the potential importance and relevance of PMS in a practical context, describing how:

academic music education always faces the problem of balancing the "musician attitude" and the "scholar attitude". However legitimate an autonomous aesthetics ('shut up an' play yer guitar') may be on the part of the professional musician, it is clearly inadequate on the part of students trained for future work as music teachers or musicologists (1993: 71).

In other words, the value of theoretical courses to practitioner students is recognised here, and is validated through the survey above.

By examining the context that is presented through PMS, clear benefits to practice become evident. Further, the skillset required to engage successfully with PMS is also relevant to a performing artist career trajectory. This is most evident when post-graduation outcomes are considered. A successful $21^{\text {st }}$ century popular music practice program is one that graduates multi-skilled and flexible performing artists who are able to engage with multifarious aspects of both the music industry and related (and often non-related) industries. This is most commonly known as the portfolio career, which requires transferable skills, both specialist and generic, and which increasingly are contained within the umbrella of 'the cultural industries, which are more broadly defined to include categories such as film and video, motion pictures, television, art galleries, libraries, archives, museums, botanic gardens, music and theatre, 
performing arts venues, and services such as education' (Bartleet et al. 2012: 33). AB supports this, and essentially refers to the portfolio musician in proposing that 'Popular Music Studies as a whole ... should be interested in creating versatile graduates, flexible graduates ... because it's a daft programme that thinks they can qualify people as musicians and that they can then expect to get jobs' (Cloonan and Hulstedt 2012: 23). Lebler supports this from a PMP context, describing how as society becomes more complex and information-rich, people need to constantly re-think, be adaptable, and develop new problem-solving strategies for new challenges. Therefore, students need to develop keen reflective thinking capabilities so they will be able to apply new knowledge to complex situations (2008: 194).

The graduate outcomes portrayed through the data analysis highlight the importance of flexibility in delivery of the various courses that make up a popular music practice program. It requires a pedagogical approach informed by disciplinary agility - 'the ability to traverse different disciplinary perspectives and terminologies. It is involved in the interaction, translation, and synthesis of knowledge between and among disciplines and sub-disciplines' (Bartleet et al, 2012: 36). Also related to portfolio careers are boundaryless careers, within which professionalism 'may be conceptualised within a framework that includes know why, know how and know whom competencies' and in which professional goals 'may be derived from the achievement of personally meaningful goals and a coherent professional self-concept' (Creech 2014: 350). While 'know how' is evidently central to a program dedicated to musical practice, 'know why' is 
especially important when, as Cloonan describes how 'anecdotal and personal experience suggests that many students struggle to see what insights sociological theory can lend to the subject (2005: 87). The concept of boundaries is also particularly relevant here, as this article began with Tagg's lamenting of the boundaries between the perceived silos of music studies and music practice. What has been demonstrated here is that with an approach that considers graduate outcomes for music practitioners, these boundaries are quite easily merged.

\section{Conclusions: the way forward}

Dai Griffiths (1999), in outlining approaches to the study of popular music, uses the metaphors of The Earnest Onlooker (sociologists), The Street Fighting Man (cultural theorists), and The Manager (music theorists), which of course mirrors those tensions found in the development of Popular Music Studies and the new musicology, and is still echoed still in Tagg's NIMiMS. Importantly (and tellingly), the practitioner is absent from this scenario. Academic discourse appears to focus on the advantages of PMS, and musicology, for academics and for the discipline, with little reference to student outcomes, and none to the practicing student musician. The results of the surveys above show clearly that this need not be the case. When theory is clearly linked to practice, students can and will engage in the theoretical aspects of music studies, but the benefits to practice must be made clear.

Not discussed in the surveys, but equally relevant is the sociological study of the music industry. Motti Regev seeks to 'better connect popular music studies with 
sociological theory, to find ways of weaving sociological theory into popular music scholarship and to use popular music expertise in order to enrich and expand the richness of sociological theorization" (2015: 36). Some of the ways he suggests to achieve this are through study of stylistic diversification, the role of the music industry in cultural production, consumption patterns, and the role of the cultural industries in influencing taste patterns (2015). Understanding the music industry in this way would clearly be of benefit to an emerging artist seeking to navigate their way to success through industry dynamics and nuances. The survey results clearly showed that incorporating PMS integrated with musicology into PMP benefitted students through:

- Developing critical listening skills

- Informing songwriting capabilities

- Developing vocational skills related to teaching

- Developing vocational skills related to a range of functions related to a musical career

- Contributing to a sense of place and role within the music industry

Bennett suggests that 'PMS may not necessarily be the first port of call in providing a scholarly context to underpin the learning of students who wish to create popular music' and that we should 'not necessarily expect its students to be better players or singers as a direct result of studying musicology' (2017: forthcoming). The analysis above suggests that while the first part of this claim may be true, the latter is more nuanced. While the survey did not give evidence of any positive impact of PMS on playing ability, it did have a positive impact on 
composition. Anecdotally and informally however, students have asserted that the critical listening skills they develop through their PMS and musicology studies do indeed lead to self-directed improvement of their playing skills (see for example Lebler 2007). Cloonan claims that 'at its best, PMS offers all citizens the chance to understand their world better and, more importantly, try to change it. Here PMS scholars offer resources of hope (2005: 90). I would argue here that Popular Music Practice students have been denied this citizenship, and that this lies at the heart of the text and context divide.

Returning to Tagg's goal, as stated on the NIMiMS site, of 'integrating the sounds of music into the study of culture and society', I propose integrating music as sounds, and music as theory into PMS. 'It is vital that a sociological analysis of popular music recognizes that the music itself is a central resource for how musical meaning is generated' (Marshall 2011: 169). Not only the practitioner, but also scholars of popular music in general, and the discipline itself as well would benefit. Lacasse describes 'a centripetal movement of disciplinary coalescence', noting that the movement is characterised by an interaction between people (and ideas), already well established within their respective disciplines, that the recent recognition of popular music as a valid object of study has allowed to coalesce for the purpose of popular music studies, while at the same time contributing to their own disciplinary challenges (2015: 73, italics in original). 
Lacasse includes scholars of pedagogical theory in this trans-disciplinarity, which is promising, and only one step away for asking said scholars to consider the role of this trans-disciplinarity in the development of the popular music practitioner. This approach would result in far better outcomes for both scholars and practitioners of popular music than the institutionalised separation of the study of popular music from the study of its practice that manifests as the Nothing-But-Music-Studies and Nothing-But-Music Practice referred to at the start of this article. This means putting the 'music itself' as practice, and its practitioners, at the intersection of the critical and the vocational, rather than at the periphery. 


\section{References}

Bartleet, Brydie-Leigh and Dawn Bennett, Ruth Bridgstock, Paul Draper, Scott Harrison, Huib Schippers (2012). 'Preparing for portfolio careers in Australian music: Setting a research agenda', Australian Journal of Music Education, 1:32, pp. $32-41$.

Bennett, Andy (2008). 'Towards a Cultural Sociology of Popular Music', Sociology, 44:4, pp. 419-432.

Bennett, Joe. (forthcoming 2017). 'Towards a Framework for Creativity in Popular Music Degrees' in G.D. Smith, G.D., Z. Moir, M. Brennan, S. Rambarran \& P. Kirkman (eds.), The Routledge Research Companion to Popular Music Education, Abingdon: Routledge.

Bjornberg, Alf (1993). '"Teach You to Rock"? Popular Music in the University Music Department', Popular Music. 12:1, pp. 69-77.

Cloonan, Martin (2005). 'What is Popular Music Studies? Some Observations', British Journal of Music Education, 22:1, pp. 77-93.

Cloonan, Martin and Hulstedt, Lauren (2012). 'Taking Notes: Mapping and Teaching Popular Music in Higher Education'. Report prepared for the Higher Education Academy, UK. 
Cloonan, Martin and Hulstedt, Lauren (2013). 'Looking for Something New: The Provision of Popular Music Studies Degrees in the UK'. IASPM@Journal: Journal of the International Association for the Study of Popular Music, 3:2, pp. 63-77.

Covach, John (2001). 'Popular Music, Unpopular Musicology' in Rethinking Music, N.Cook and M. Everist (eds.), Oxford: Oxford University Press, pp. 452-470.

Creech, Andrea (2014). 'Understanding Professionalism: Transitions and the Contemporary Professional Musician' in G. Welch (ed.), Advanced Musical Performance: Investigations in Higher Education Learning, Farnham, Surrey: Ashgate Press, pp. 349-364.

Fitzgerald, Jon (2007). 'Tertiary Popular Music Studies in the 21 ${ }^{\text {st }}$ Century: Some Perspectives from Eastern Australia and Eastern Canada', in NACTMUS (National Council of Tertiary Music Schools), National Conference on Music in Australian Tertiary Institutions, Griffith University, 29 June - 1 July Brisbane, Australia.

Fitzgerald, J., \& Hayward, P. (2004). 'Alternative Mixes: a Comparative Discussion of the Contemporary Music Programs at Macquarie and Southern Cross Universities'. Proceedings of the XXVIth Annual AARME (Australian Association for Research into Music Education) Conference, Melbourne, Australia.

Griffiths, Dai (1999). 'The High Analysis of Low Music', Music Analysis, 18:3, pp. 389-435. 
Hawkins, Stan (2001). 'Musicological Quagmires in Popular Music: Seeds of

Detailed Conflict', Popular Musicology Online, 1, UK. Accessed March 2014.

Hesmondhalgh, David, and Negus, Keith (2002). Popular Music Studies. Oxford:

Oxford University Press.

Lacasse, Serge (2015). '(Re)generations of Popular Musicology' in A. Bennett and S. Waksman (eds.), The Sage Handbook of Popular Music, London: Sage Publications, pp. 64-82.

Lebler, Don (2007). 'Student-as-master? Reflections on a Learning Innovation in Popular Music Pedagogy', International Journal of Music Education, 25:3, pp.205221.

Lebler, Don (2008). 'Popular Music Pedagogy: Peer Learning in Practice', Music Education Research, 10:2, 193-213.

Lebler, Don and Weston, Donna (2015). 'Staying in Sync: Keeping Popular Music Pedagogy Relevant to an Evolving Music Industry', IASPM@ Journal, 5:1, pp. 124138.

Mantie, Roger (2013). 'A Comparison of “Popular Music Pedagogy” Discourses', Journal of Research in Music Education, 61:3, pp. 334-352. 
Marshall, Lee (2011). 'The sociology of popular music, interdisciplinarity

and aesthetic autonomy', The British Journal of Sociolog,y 62:1, pp. 154-174.

Middleton, Richard (1993). 'Popular Music Analysis and Musicology: Bridging the Gap', Popular Music, 12:2, pp. 177-190.

NIMiMS: Network for the Inclusion of Music in Music Studies.

http://nimims.net/\#NewSite. Accessed 7 July 2016.

Regev, Motti (2015). 'Notes on Sociological Theory and Popular Music Studies' in A. Bennett and S. Waksman (eds.), The Sage Handbook of Popular Music, London: Sage Publications, pp. 33-47.

Tagg, Phillip (2004). 'Text and Context as Corequisites in the Popular Analysis of Music'. Paper prepared for conference on Musical Text and Context, Cremona, April 2002 by Philip Tagg. Available from http://tagg.org/articles/cremona.html. Accessed 7 July 2016.

Tagg, Phillip (2012). Music's Meanings: a Modern Musicology for Non-Musos, Mass Media's Scholar's Press.

Weston, Donna and Byron, Tim (2015). 'Killing the Muse: Listening Creativities and the Journey to Creative Mastery' in P. Burnard and E. Haddon (eds.), Activating Diverse Musical Creativities: Teaching and Learning in Higher Music Education, London: Bloomsbury, pp. 57-74. 
